\title{
HIGH EARTHQUAKE RISK BUILDINGS
}

\author{
The following papers were presented at a Seminar on High Earthquake \\ Risk Buildings held in Wellington on 6 October, 1973. They form \\ part of the published proceedings, copies of which may be obtained \\ from the Administrative Secretary.
}

\section{A PHILOSOPHYFOR IMPROVING OLD BUILDINGS TO RESIST EARTHQUAKES}

\author{
J. P. Hollings*
}

\subsection{INTRODUCTION:}

This paper assumes that the assessment of a particular building under the Municipal Corporations Act has shown that the building must be either destroyed or in some way given an improved resistance to earthquakes.

This paper discusses the various problems inherent in making improvements and makes recommendations for minimum standards for such work. Since the Municipal Corporations Act is intended to deal mainly with old brick buildings and since, as a class, this is by far the largest risk, the discussion and recommendations of this paper have also been limited to brick structures.

\subsection{OBJECTIVES FOR IMPROVEMENTS IN EARTHQUAKE RESISTANCE:}

There are some buildings for which an indefinite life is required after the improvements are complete. Examples are old buildings of historic value which it is in the national interest to preserve. There is little point in improving the earthquake resistance of such buildings unless it can be done as a permanent proposition.

If an indefinite life is required, it is here postulated that the improved buildings must equal the earthquake resisting standards of modern buildings which are intended for an indefinite life.

Here we must be careful to avoid confusing the means and the end. The primary end or objective of a modern design is that it should be able to resist the largest earthquake which can be expected in the area where the building is to be built; and it must do this without loss of life. Here we can note that this is so irrespective of zoning provisions. In zones of lower earthquake risk, the modern designs are still intended to protect life though, in the event of a major earthquake, structural damage will be greater and more widespread due to the lower design standards of that zone.

Thus, our old building intended for

* Beca Carter Hollings \& Ferner Ltd. , Consulting Engineers, Wellingțon. indefinite life must be so improved, wherever it may be, that the most serious earthquake will not cause loss of human life.

\subsection{MODERN CODES NOT APPLICABLE :}

The end is the same for well designed modern and for improved old buildings: i.e. protection of human life. However, it is a mistake to suppose that the means used to achieve this in modern buildings can be applied to old ones with success. The argument goes as follows:-

Our current codes for designing an earthquake resistant structure provide a level of strength considerably below that which the structure would require if they were to remain elastic and undamaged in a major earthquake. In spite of this low strength, modern structures have a high resistance to collapse and therefore give high protection to human life because of their inherent ductility. It is this ductility or toughness, not their strength, which is essential.

In contrast, the generality of brick buildings are inherently non-ductile or brittle. In fact this is the most striking natural feature of these old buildings. They are made up of innumerable small elements not bonded together effectively and often relying solely on gravity to hold them together. The result is that a moderate shaking is usually all that is needed to cause the structure to separate into its component parts with an immediate collapse following.

It is for this reason that present tentative City Council strengthening rules which are based on present codes are, in the writer's opinion, misleading and dangerous. It is true they will produce some improvement in earthquake resistance but, because they are based on a wrong principle, they may still leave a building which can collapse even in a moderate shaking.

It is asserted here that what is required is a different approach - one that is based on practical improvements to the major physical defects inherent in brick structures as a type rather than on increases 
in nominal calculated lateral strength. Strength increases are often necessary but this should come second after improvements in principle have been effected.

\subsection{PRACTICAL PROPOSALS FOR IMPROVEMENTS TO RESIST EARTHQUAKES:}

These thoughts plus a consideration of what is physically practicable with an old structure, plus some experience with the high costs of strengthening, have led to the proposal below for three levels of improved resistance - the third, or highest, gives an indefinite life, the others should have a restricted life. are:-

The proposed levels of improvements

hazards.

ii) Addition of independent floor support and veneering of walls.

(iii) Addition of independent lateral strength in ductile frames or shear walls.

\section{Discussing these in turn:-}

(i) Not only do brick structures tend to disintegrate into the individual bricks because they are not tied together, but they also tend to disintegrate into individual structural elements - also through lack of tying.

A first practical step then is to secure the structural elements together so that the whole building acts as a structural unit and all of its available strength is mobilised. Thus joists must be prevented from slipping off beams or girders, girders from slipping off walls or columns. In addition floors can be converted into shear resisting diaphragms and effectively connected to walls. At the same time as these measures, obvious hazards not easily strengthened can be removed - e.g. tall unreinforced chimneys or parapets.

(ii) An important characteristic of most brick structures which are to be considered for strengthening is that the brick walls serve the double purpose of both supporting the floors and of providing lateral strength to help resist wind and earthquake. Often only a moderate shaking is required to destroy the integrity of the brickwork and thus to lose both lateral strength and floor supporting capacity. Of these the latter is by far the most important and is vital if the life of the inhabitants is to be protected. This leads to the suggestion that a pronounced upgrading in the lifesaving property of the structure will be achieved if new support for the floors is provided independently of the brick walls. This can usually be done quite conveniently using timber or light steel members.

The floors are now secured but the disintegrating walls, as they are exposed to earthquake shearing forces, will still be a threat to persons in and around the building. In addition, especially in the upper stories, brick walls are usually poor in resistance to so-called "face loads" which may cause an entire panel to fall out. This leads to the suggestion that such walls should be converted to brick veneer walls. This can usually be done easily by grouting in fixings to the surface of the brickwork at quite close intervals and by then attaching these fixings to the new floor supports.

The second suggested level of improvement then is to give the floors independent support and at the same time to convert the brick walls to veneers by giving them frequent lateral support.

(iii) For a structure intended for indefinite life, the final step is to provide some lateral strength independent of the brick walls. This may be in the form of new concrete shear walls or as flexible steel or concrete frames. The former act in conjunction with the brick walls, the latter do not come into effect until after the brick walls have been seriously damaged. (This will not matter, however, if the independent floor and wall support suggested above has been provided.)

Because of these measures already taken for floor and wall support, it is not too important what levels are selected for lateral strength and the forces actually chosen may be relatively arbitrary without much affecting the total earthquake performance. Moreover, once the system has been selected in principle, the level of lateral force chosen does not have a big influence on the total cost of the improvements. In addition simplicity is most desirable.

This author's suggestion therefore is that the basic seismic coefficients of NZSS 1900 Chapter 81965 be used for structures on soft ground. These may be modified by a factor of $2 / 3$ where the designer is satisfied the foundations are very firm hard ground. (The comparatively heavy penalty for soft ground is a result of recent studies in the author's office on frequency of soft ground attack - see Ref. 1.) It is suggested also that the " $K$ " factors of the SEAOC codes are also appropriate: i.e. where the strengthening system is shear walls, the lateral loads should be factored by a further 1.33 and where thissystem is a $25 \%$ frame (refer to SEAOC for detail), an 0.8 factor may be used.

Thus, where a structure has been improved in this way for indefinite life, it may reasonably be expected to resist a major earthquake without collapse. The expected performance in such an event would be that the brick walls would suffer progressive and increasing damage, thus dissipating the energy of the earthquake until towards the end of a major event the added strengthening system would be doing most of the lateral resisting work. At that stage the bearing walls may well be seriously cracked and close to rubble but the floors are still held up by the new system provided which also prevents the walls themselves from falling into or outside the building.

\subsection{PRACTICAL PROBLEMS AND COSTS OF IMPROVEMENTS FOR INDEFINITE LIFE}


The writer has had some experience in attempting to strengthen old buildings using the techniques described above.

Considerable ingenuity and invention is often required in devising suitable details for new connections both between parts of the old structure and from new work to old structure. However this is by no means beyond the capacity of an experienced structural engineer and most can cope. though with perhaps varying success.

The real problems arise in keeping the total cost within reason and this is in spite of the fact that the added works may be quite modest in their intrinisic value. This difficulty occurs because of the high labour costs which are always associated with strengthening operations. These include drilling holes on site in restricted spaces; manhandling new structural members into place because there is no access for cranes; fitting new work to old with consequent lack of fit and necessary on-site adjustment. In addition to structural costs, the cost of improvements to make the building rentable by today's standards (e.g. new lifts, better lighting, better fireproofing, etc.) are usually also high.

Apart from and in addition to the costs of improvements, there is the consideration that the improved building is likely to be sub-standard operationally when completed - e.g. poor natural light and ventilation. Further, there is the problem of site usage. Land is rising in value and for a satisfactory financial return on the site, it is usually necessary to exploit fully the plot ratio allowances of the current town planning ordinances. The old building is likely to be quite unsatisfactory in this respect.

The nett result of all these factors is that when total costs and benefits are taken into account, it is usually economically better to demolish and rebuild to modern standards which fully exploit the site rather than to attempt to make improvements for indefinite life.

There will be exceptions to this general rule and examples as already noted are structures of historic or sentimental value which the community is prepared to pay to preserve.

\subsection{IMPROVEMENTS FOR LESS THAN INDEFINITE LIFE:}

Where the local body is prepared to accept some risk to human life, then structural improvements to lower standards than the above, with limitations on the life of the building, are a possibility.

Because the costs of re-decoration, new lifts, better ventilation, poor site usage etc. are usually dominant in any economic study for a renewal scheme, structural improvements for even a short life are usually difficult to justify economically.

However, there will always be some owners who will wish to study this possibility, if not to adopt it, and the question then is what policy should local authorities adopt on this question.
This will always be a matter for individual judgement and there are many factors to influence this judgment. Some of them are :-

(i) If less than the indefinite structural life proposals outlined above are accepted, there will be some risk to human life.

(ii) In any major earthquake not all those brick buildings which should theoretically collapse, do so. This is due to peculiarities of local ground conditions, direction of earthquake attack, support from adjacent buildings, etc.

(iii) Temporary life proposals must be long enough to allow a reasonable return on the capital invested or they are not worth considering.

(iv) The frequency of attack of damaging earthquakes and therefore the total risk when the urban population as a whole is considered, is much less than usually supposed (Ref. 1).

With these in mind, the author's suggestions are:-

\section{5 year proposals:}

Improvements as in para 4.0 (i) above with also a minimum lateral strength of one-third of that suggested for indefinite life. (i.e. 4.0 (iii))

30 year proposals:

Improvements as in paras 4.0 (i) and 4.0 (ii) above with also a minimum lateral strength of two-thirds of that suggested for indefinite life. (i.e. 4.0 (iii) ).

\subsection{CONCLUSION:}

The essential points made in this paper may be summarised:-

1. Structural improvements intended to give old buildings indefinite life must be based on first principles, not on "strengthening to code standards" - or any fraction thereof.

2. For indefinite life:-

(i) The component parts must be tied.

(ii) Independent vertical support is required for floors. Independent lateral support is required for walls.

(iii) An independent lateral strength system is required.

3. The high costs of re-furbishing old buildings and their general obsolescence usually mean that, when structural improvements are also taken into account, indefinite life proposals are rarely an economic possibility.

4. Structural improvements for a reduced building life are reasonable provided the local authority concerned is prepared to accept some risk to human life.

REFERENCE :

"The Selection of Seismic Design Loadings by the Use of Return Period Graphs" - by Hollings and Dellow. Fifth World Conference on Earthquake Engineering - Rome 1973. 